\title{
REPRESENTACIÓN Y TRAUMA Un aporte a la complejidad del tema
}

\author{
Representation and Trauma
}

A Contribution to the Complexity of the Issue

Marcela Andruchow | marcela_andruchow@yahoo.com.ar

Museología | y ||

Facultad de Bellas Artes

Universidad Nacional de La Plata

Argentina

Recibido: 27/1/2018

Aceptado: 11/4/2018

\section{RESUMEN}

Este artículo realiza un aporte a la complejidad del tema de la representación y el trauma desde su repercusión en las producciones estéticas. A partir de un relevamiento y de un análisis bibliográfico selectivo, plantea la necesidad de abordarlo con una metodología transdisciplinaria. A través de un ejemplo del fetichismo narrativo, expone que toda aproximación al problema de la representación y del trauma no pude evitar considerar la teoría del trauma.

\section{PALABRAS CLAVE}

Representación; trauma; elaboración; fetichismo narrativo

\section{ABSTRACT}

This article tries to make a contribution to the complexity of the issue of representation and trauma from their impact on aesthetic productions. From a survey and selective bibliographical analysis, it raises the need to tackle it with a transdisciplinary methodology. Through an example of the narrative fetishism, it sets out that any approach to the problem of representation and the trauma could not escape to deal with the trauma theory.

\section{KEYWORDS}

Representation; trauma; narrative elaboration; fetish 
Este artículo ofrece algunos aportes a la complejidad del tema de la representación de la masacre histórica, entendida como el asesinato masivo de individuos en condiciones de indefensión (Burucúa \& Kwiatkowski, 2014) y su corolario de memoria traumática, con relación a los debates surgidos en las últimas décadas del siglo XX. Estos crímenes perpetrados mayormente por el Estado y socialmente motivados -aunque no en todos los casos- están conectados con ideologías, tales como el fascismo, el nacional socialismo, el racismo, el socialismo de Estado, la eliminación étnica, los fundamentalismos religiosos o el terrorismo de Estado, en el caso de América Latina.

La discusión acerca de las representaciones posibles de estos sucesos de catástrofe humana ha sido abordada por distintos especialistas a lo largo de las últimas tres décadas. El presupuesto que subyace a este debate es que se trata de un cierto tipo de acontecimientos que exige un tratamiento global y una reflexión general sobre las dificultades que entraña su representación (Friedlander, 2007). A partir de la década de 1980, el tropo fundamental en torno al que han discurrido estas cuestiones de representación y de narración ha sido el Holocausto, entendido como situación límite que exige un esfuerzo desconocido para poder ser atrapado en las narrativas conocidas. Al respecto, Saul Friedlander sostiene:

\section{Lo que hace de la solución final un suceso límite es el hecho de ser la forma más radical de genocidio que encontramos en la historia: el intento voluntario, sistemático, industrialmente organizado y ampliamente exitoso de exterminar por completo un grupo humano en el marco de la sociedad occidental del siglo XX (2007, p. 23).}

A su vez, el autor recupera la reflexión de Jürgen Habermas, quien explica:

\footnotetext{
Alli [en Auschwitz] sucedió algo que hasta ahora nadie había pensado siquiera que era posible. Allí se alcanzó a tocar algo que representa la capa más profunda de solidaridad entre todo aquello con rostro humano; a pesar de todos los habituales actos de bestialidad de la historia humana, siempre se había dado por sentado que esa capa común era algo sólido [...] ha alterado las bases para la continuidad de las condiciones de la vida en la historia (Habermas en Friedlander, 2007, p. 23).
}

Lo esperable es que acontecimientos tan monstruosos como éste no puedan ser olvidados o reprimidos. Sin embargo, en estos episodios los perpetradores no solo asesinaron a las víctimas sino que 
1 Dentro de esta posición que se aleja totalmente de las posturas negacionistas o del pensamiento posmoderno que postula la imposibilidad de abordar la realidad más allá de la mediación del lenguaje, podemos mencionar a una serie de autores que discuten el tema en torno a la idea de que lo importante es qué se quiere representar y qué modo de representación se elige para ello. Entre estos autores se encuentran Jean-Francois Lyotard, Carlo Guinzburg, Jacques Ranciere, George Didi-Huberman, Pierre Vidal Naquet, Susan Sontag, Dominick LaCapra. (Burucúa \& Kwiatkowski, 2014). hicieron grandes esfuerzos para ocultar y borrar las evidencias de sus acciones. Frente a esto, la exigencia de recordar, de registrar y de dar testimonio de ese pasado se vuelve indispensable. Pero las masacres fueron tan terribles que se quebraron las cadenas de causas y efectos $y$, por lo tanto, el lenguaje u otros medios de representación fueron insuficientes o inadecuados para describir tales sucesos.

Dentro de las posiciones acerca de la representación de estas masacres, José Emilio Burucúa y Nicolás Kwiatkowski (2014) distinguen dos que resultan especialmente interesantes. Por un lado, la exigencia de memoria y de registro llevó a la pretensión de que dicho registro evitara verse distorsionado o banalizado por representaciones inapropiadas. La narración (o la imagen visual) testimonial se asocia a una cierta pretensión de verdad que se vuelve imperativa $y$, necesariamente, queda delimitada por los requisitos que impone la evidencia material disponible. Es decir que la representación tiene límites que no deberían ser sobrepasados, pero que fácilmente pueden serlo (Friedlander, 2007). Además, esta necesidad de testimoniar y de comprender halla otro límite que es el riesgo de que la comprensión derive en algún tipo de justificación (Burucúa \& Kwiatkowski, 2014). Por otro lado, la exigencia de registro es de tono diferente pero también compromete los límites de la representación. Se refiere a que frente a lo aberrante de los acontecimientos experimentados, se impone la carencia de conceptualizaciones que permitan describir y transmitir esos sucesos. Aparece, así, la insistencia en la imposibilidad de decirlos o de representarlos (Burucúa \& Kwiatkowski, 2014).

Estas posturas conllevan consecuencias políticas, éticas y estéticas. En el caso de los defensores de la irrepresentabilidad, el argumento es que si bien el genocidio puede ser representado la única forma de hacerlo es mediante la objetividad, la literalidad y la reducción de la distancia entre el suceso y su representación. Se descarta, por lo tanto, que el tema pueda ser objeto de manifestaciones ficcionales o artísticas. ${ }^{1}$

Dentro de los defensores de la irrepresentabilidad, Georges Wajcman y Elizabeth Pagnoux defienden la imposibilidad absoluta de representación. Burucúa y Kwiatkowski sostienen que «para estos autores, los límites de la representación, son radicales, ontológicos» (2014, p. 19). No solo es imposible imaginar o representar la Shoá sino que hacerlo constituye un agravio moral.

En cuanto a la postura que piensa a la representación como posible siempre que se atienda a su adecuación - lo que implica aceptar que ésta pueda manifestarse estéticamente-, el historiador del arte Ernst van Alphen, entre otros, postula la legitimidad de una representación estética del Holocausto, con el énfasis dramático y emocional que

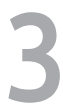


llegue a alcanzar. El autor resalta que el efecto evocativo que una obra de arte contemporáneo puede lograr supera con contundencia la de un relato o narración. Según este autor, «el Holocausto no es representado sino más bien presentado, reactuado. [...] No se hace presente [...], como un relato mediado [del lenguaje], sino que se hace presente en calidad de efecto performativo" (van Alphen en Burucúa \& Kwiatkowski, 2014, p. 23). ${ }^{2}$ En apoyo a este planteo y en términos más amplios, podemos recuperar la reflexión de Dominick LaCapra:

\section{[... una idea «psicoanalítica» del arte en el período moderno consistiría en verlo de manera no reduccionista como un refugio relativamente «seguro» y a menudo desconcertante o como un sitio especial donde explorar la reactuación sintomática y el intento de elaborar o superar acontecimientos o conflictos extremos (2006, p. 27)}

Esto implica no solo que la representación de eventos traumáticos como el genocidio puede ser abordada en clave artística, sino que el arte puede colaborar con los procesos de elaboración de las experiencias traumáticas mismas.

Con relación a esto último, es importante señalar que el problema de la representación no se agota en representar o en aferrarse a la irrepresentabilidad, en qué o en cómo representar, o en si el arte es un ámbito propicio para la representación del horror del genocidio. El hecho de que los acontecimientos referidos estén asociados a experiencias traumáticas complejiza el abordaje del problema, dado que para poder recomponer y representar lo destruido por el genocidio se hace necesario comprender el trauma irrepresentable (Burucúa \& Kwiatkowski, 2014).

La discusión acerca de la representación no puede eludir, entonces, el tratamiento de su relación con el trauma ${ }^{3}$ y con la experiencia traumática. En especial para las víctimas, el trauma genera un lapsus o ruptura en la memoria que interrumpe la continuidad con el pasado y que produce un cimbronazo en la identidad. El acontecimiento traumático resulta reprimido o negado y queda oculto a la conciencia. Pero lo que se niega o se reprime de la memoria no desaparece sino que regresa de un modo transformado, deformado o desfigurado. $Y$ esos recuerdos del trauma se expresan al revivir, repetir o pasar al acto compulsivamente las escenas traumáticas del pasado, mediante procesos más o menos controlados. Esta condición de las víctimas afecta por extensión a quienes entran en contacto con ellas por la tendencia a involucrarse emocionalmente con el testigo y su testimonio e implican la inclinación a actuar una respuesta afectiva que dependerá de la posición subjetiva de esos testigos secundarios (LaCapra, 2009).
2 Se puede complejizar este planteo y vincularlo al problema de expresarse como oposición a elaborar (LaCapra, 2007). En el sentido de que expresarse podría quedar sujeto a la acción performática de la "compulsión a la repetición», mientras que elaborar alude a la posibilidad de realizar el trabajo de duelo. Ambas acciones podrían ser parte de las consecuencias de episodios extremadamente traumáticos. En términos de LaCapra: «El intento de reconciliarse con sucesos sumamente traumáticos implica el trabajo de duelo» (2007, p. 196); y expresarse puede ser inevitable en el proceso de dicho trabajo.
3 Para el psiconálisis «el trauma, designa, ante todo, un acontecimiento personal en la historia del sujeto, cuya fecha puede establecerse con exactitud, y que resulta subjetivamente importante por los efectos penosos que puede desencadenar. No puede hablarse de acontecimientos traumáticos de un modo absoluto, sin tener en cuenta la susceptibilidad propia del sujeto. Para que exista trauma en sentido estricto, [debe producirse una] falta de abreacción (descarga de emociones y afectos ligados a recuerdos) de la experiencia (Laplanche \& Pontalis, 1971, pp. 468-469). 
(4 Entendiendo que el proceso de elaboración implica una distancia emocional con el trauma para que la víctima pueda posicionarse como observador participante, lo que permite presentificar el mismo. Este continuum posibilita la sensopercepción de la memoria secundaria.
La experiencia traumática no es puntual y tiene un aspecto evasivo porque se relaciona con un pasado que no ha muerto. En la denominada memoria traumática (memoria primaria), el pasado continúa vivo en el nivel experiencial y atormenta o posee al yo o a la comunidad (cuando las experiencias traumáticas son compartidas). Es necesario elaborar ese pasado -a través de procesos como la narración, el duelo y el pensamiento y la práctica críticos- para poder recordarlo con cierto grado de perspectiva crítica y control consciente que permita la supervivencia y la capacidad de acción ética y política en el presente (LaCapra, 2006). El trauma debe ser elaborado, solo así puede recuperarse una memoria, en este caso secundaria, ya que como el acontecimiento traumático no está integrado a la experiencia ni es recordado directamente, solo puede ser reconstruido a partir de sus efectos y de sus marcas. En este sentido, no existe acceso consciente pleno y directo a la experiencia del acontecimiento, ni siquiera para la víctima, y menos para el testigo secundario (o para el historiador). Y en la medida en que sí existe un acceso inmediato al suceso traumático por medio del revivir o del pasaje al acto del acontecimiento, la memoria queda obturada y la elaboración requiere que ese pasaje al acto se complemente con la memoria secundaria y con otros procesos relacionados (LaCapra, 2009). ${ }^{4}$

Lo desarrollado contribuye a dimensionar el nivel de complejidad de los procesos implicados en el intento de representación del acontecimiento. El caso que mejor permite mostrar la magnitud de estos procesos es un tipo particular de representación que Eric Santner califica de «fetichismo narrativo»:

[La] construcción y el despliegue de una narrativa ideada para borrar las huellas del trauma o de la pérdida. El uso de la narración como fetiche contrasta con [...] el comportamiento simbólico que Freud designó Trauerarbeit o «trabajo de duelo». Tanto el fetichismo narrativo como el duelo son respuestas a una pérdida, a un pasado que se resiste a marcharse por obra de su impacto traumático. El trabajo de duelo es un proceso en el que se elabora e integra la realidad de la pérdida o del shock traumático, recordándola, repitiéndola en dosis mediadas simbólica y dialógicamente. [...] el fetichismo narrativo, por oposición, es la forma en que la incapacidad — o la negativa - de hacer duelo pone en una trama a los sucesos traumáticos; es la estrategia de desarticular en la fantasía la necesidad de hacer duelo, simulando que se está intacto, normalmente situando el escenario y el origen de la pérdida en algún otro lugar. El fetichismo narrativo alivia el peso de tener que reconstruir la propia identidad en condiciones «postraumáticas»; en él, el «pos» significa postergación indefinida (2007, pp. 221-222). 
El fetichismo narrativo procura, de manera voluntarista, apelar al placer como efecto de la representación y negar los afectos penosos que conlleva el trabajo de duelo para la psiquis, ya que ofrece la certeza de que no hay necesidad de elaborar el trauma. Santner ejemplifica este concepto al analizar la película Heimat (1984), de Edgar Reitz, un film que retoma la escena de la Alemania de preguerra. Allí, Reitz se niega a permitir que los momentos potencialmente traumáticos interrumpan la economía del placer narrativo y visual de su largometraje, concentrándose en la historia de amor que enlaza la película y dejando solo como telón de fondo el drama judío en la Alemania Nazi (Santner, 2007).

Por lo expuesto, se puede concluir en que toda aproximación al tema de la representación de una catástrofe humana no puede eludir trabajar interdisciplinariamente la teoría del trauma o, al menos, presentar las dificultades que su tratamiento plantea tanto con relación a la representación en la narrativa histórica como a la artística.

Delinear un aporte a esta problemática inevitablemente pone de relieve la complejidad de un tema en el que convergen aspectos históricos, artísticos, políticos, éticos, estéticos, psicológicos, antropológicos, es decir, un conjunto de procesos culturales que atraviesan a cada uno de los individuos en forma particular de acuerdo a como hayan sobrevivido a ellos. Obviamente, el nivel de complejidad esteriliza cualquier intento de definición o de conclusión cerrada, ya que ni social ni individualmente los procesos traumáticos, como aquí se intenta plantear, concluyen por ser esencialmente dinámicos y mutantes. Por lo tanto, se puede pensar que la representación del trauma tiene la premisa de ser incompleta y fallida.

\section{REFERENCIAS}

Burucúa, J. E. y Kwiatkowski, N. (2014). Cómo sucedieron estas cosas. Representar masacres y genocidios. Buenos Aires, Argentina: Katz.

Friedlander, S. (Comp.). (2007). En torno a los límites de la representación. Bernal, Argentina: Universidad Nacional de Quilmes.

International Council of Museums. (2001). Plea for the creation of an International Committe for Memorial Museums for Public Crimes against Humanity. Recuperado de http://network.icom.museum/ fileadmin/user_upload/minisites/icmemo/pdf/plea_ICMEMO.pdf

LaCapra, D. (2006). Historia en tránsito. Experiencia, identidad, teoría crítica. Buenos Aires, Argentina: Fondo de Cultura Económica. 
LaCapra, D. (2007). Representar el Holocausto: reflexiones sobre el debate de los historiadores. En S. Friedlander (Comp.). En torno a los límites de la representación, (pp. 171-198). Bernal, Argentina: Universidad Nacional de Quilmes.

LaCapra, D. (2009). Historia y memoria después de Auschwitz. Buenos Aires, Argentina: Prometeo.

Laplanche, J. y Pontalis, J. B. (1971). Diccionario de psicoanálisis. Madrid, España: Labor.

Santner, E. (2007). La historia más allá del principio del placer: algunas ideas sobre la representación del trauma. En S. Friedlander (Comp.). En torno a los límites de la representación, (pp. 219-258). Bernal, Argentina: Universidad Nacional de Quilmes. 